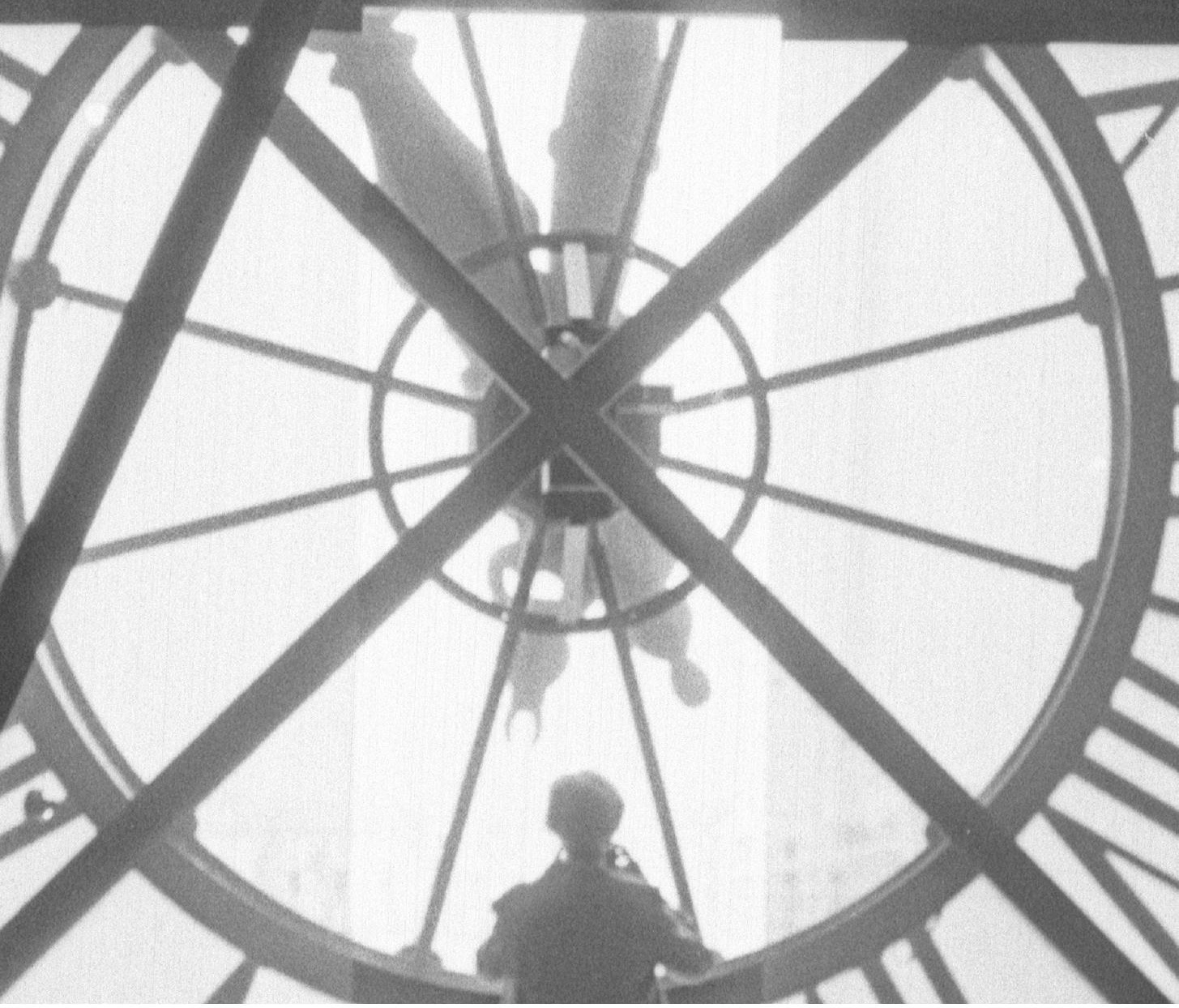

AIBR

Revista de Antropología Iberoamericana

www.aibr.org

Volumen 11

Número 1

Enero - Abril 2016

Pp. 59 - 77

Madrid: Antropólogos

Iberoamericanos en Red.

ISSN: 1695-9752

E-ISSN: 1578-9705

\section{En el mundo de hoy, la antropología es más importante que nunca}

\section{Maurice Godelier}

École des hautes études en sciences sociales

Enviado: 20.04.2015

Aceptado: 15.12 .2015

DOI: 10.11156/aibr.110104

Traducción: Hélène Giguère 


\section{RESUMEN:}

Tras la caída del colonialismo europeo en el siglo XX, el mundo intelectual occidental experimentó una profunda crisis de conceptos, métodos y legitimidad. Occidente se convirtió en "otro» Occidente, y fue en ese entorno donde la disciplina antropológica, cuya labor era precisamente conocer a otras sociedades, experimenta un proceso de crisis y deconstrucción. Por un lado esta crisis plantea la desaparición del objeto de estudio de la disciplina, de esas sociedades "primitivas", pero por otro esa deconstrucción sienta a su vez las bases para reconstruir los fundamentos que otorgan relevancia a la profesión antropológica. A lo largo de este texto se ilustran numerosos ejemplos sobre cómo la labor etnográfica es esencial en los procesos de interpretación científica de la actual diversidad social, especialmente porque los objetos de estudios tradicionales de la disciplina son consecuencias de procesos que constantemente se repiten, creando nuevos y diversos grupos sociales. Para ello se ilustran casos de sociedades o incluso Estados que se formaron con posterioridad a la etapa colonial, desde los baruya o tikopia hasta el Estado de Arabia Saudita.

PALABRAS CLAVE:

Antropología, colonialismo, crisis, Occidente.

\section{IN TODAY'S WORLD, ANTHROPOLOGY IS MORE IMPORTANT THAN EVER}

\section{ABSTRACT:}

After the collapse of the European colonialism in the 20th Century, the intellectual Western Word was part of a crisis, which called into questions its own concepts, methods and more fundamentally their legitimacy. The Western World became "another" Western World, and in that context, the discipline, that supposedly explored other societies, experimented a process of deconstruction. On the one hand, this crisis portrays the disappearance of the object of study in the discipline, the "primitive" societies; but on the other hand, it settles down the basis to reconstruct the profession of the anthropologist as a fundamental element in our world. This articles illustrates several examples of the fundamental role that anthropology plays today in the task of serving the scientific interpretation of social diversity. Traditional objects of study in the discipline come back over again and provoke the creation of new and more diverse social groups. This was the case of societies that were formed after the colonial period, including the Baruya, Tikopia, as well as the recent creation of Saudi Arabia.

KEY WORDS:

Anthropology, colonialism, crisis, Western World. 
Mis primeras palabras serán para agradecer el profesor Karl-Heinz Kohl y sus colegas del Frobenius Institut por haberme invitado a participar en este ciclo de conferencias cuyo tema es The End of Anthropology (El fin de la antropología). Este tema para algunos de nuestros colegas está experimentado como un temor; por otros, al contrario, es un deseo, una expectativa. Para mí —y no soy el único en pensarlo— aquel problema está ya superado.

Cualesquiera que sean las reacciones que uno pueda tener frente esta cuestión, esta nació hace unos años, a partir de los años 1980 en antropología y un poco antes en las disciplinas literarias, las ciencias sociales y las humanidades, cuando estas disciplinas entraron en un período de crisis: crisis de conceptos, crisis de métodos, y más profundamente, crisis de legitimidad. En efecto, algunos de nuestros colegas empezaron entonces a denegar toda autoridad científica a los trabajos de los antropólogos que les habían precedido, así como a las obras producidas antes de que hubieran tomado conciencia del carácter ficticio e ideológico de las «narraciones» construidas por los antropólogos occidentales para dar a conocer lo que pretendían haber entendido de la naturaleza de otras formas de cultura y de sociedad.

Porque la cuestión clave a la cual la antropología, la historia, la arqueología y otras ciencias sociales se esfuerzan en responder desde sus orígenes, es la siguiente: ¿cómo comprender y explicar la existencia de hechos, de actitudes, de representaciones, que jamás formaron parte de nuestra manera de vivir y de pensar?

Evidentemente, esta cuestión no depende solamente del campo del conocimiento científico. Se presenta cada vez que, por diversos motivos, los individuos o grupos humanos se ven obligados a relacionarse con otros individuos o grupos pertenecientes a clases sociales diferentes en el seno de su propia sociedad, o bien a sociedades profundamente distintas de la suya. Ahora bien, comprender la alteridad del otro es descubrir el sentido y las formas de pensar y modos de vida de personas que son ajenas a uno. Es descubrir la naturaleza de las relaciones que aquellos otros mantienen entre ellos, del lugar que ocupan y de las representaciones que se hacen de él. Pero comprender no es suficiente para explicar. Explicar es procurar descubrir cómo las diferentes maneras de existir socialmente que se comprendieron aparecieron aquí y allí en el curso de la historia y se reprodujeron transformándose a veces durante algunos siglos, a menudo también durante milenios, como las grandes religiones, el Budismo, el Cristianismo, el Islam, todavía presentes en nuestra época, no sin haber conocido profundas transformaciones en el curso de los siglos. 
De Morgan a Lévi-Strauss, de Malinowski a Sahlins, los antropólogos han pensado que con la ayuda de sus conceptos y métodos, el conocimiento distanciado - y por eso relativamente objetivo- de la alteridad social y cultural de los otros era posible. Y cada uno de ellos creyó contribuir a esto a su manera. Ahora bien, es esta pretensión de conocer la alteridad de los otros y esta confianza en sus métodos, sus conceptos y sus teorías desarrolladas para alcanzar este objetivo lo que algunos de nosotros empezamos a discutir alrededor de los años 1980, provocando una crisis en la que, como veremos, todos los aspectos están lejos de ser negativos. ¿Por qué este cuestionamiento y la crisis que le siguió? Me parece necesario volver al contexto de los años 80 para entenderlo.

En 1945, Europa sale victoriosa de una guerra contra la Alemania nazi, la Italia fascista y el Japón imperialista que la deja exangüe y hace de los Estados Unidos la primera potencia mundial frente a la Rusia soviética. Es en esta nueva relación de fuerzas que, entre 1955 y 1970, los últimos imperios coloniales europeos van a desaparecer uno tras otro, al término de guerras de liberación sangrientas o de modos más pacíficos. Fue entonces imposible seguir afirmando como antaño que colonizar es civilizar y que civilizar es ayudar a otros pueblos a avanzar más rápido en el camino de los progresos alcanzados por Occidente. Liberadas de la dominación directa de las potencias europeas, las antiguas colonias, ahora naciones independientes, empezaron a desarrollarse de otro modo. Luego hubo entre 1980 y 1990 otra perturbación mundial, la descomposición acelerada y luego el hundimiento esperado de los regímenes comunistas establecidos después de la Segunda Guerra Mundial en Europa Central y Oriental, pero también en Asia, en Extremo Oriente, en África y en Cuba. De esto no quedan hoy más que escasos pedazos. Comprendemos que estas dos grandes perturbaciones hayan modificado en profundidad las relaciones de Occidente con el resto del mundo, pero también consigo mismo, y que fueran a socavar el mundo intelectual que se había instalado en Europa y en los Estados Unidos después de la Segunda Guerra Mundial.

No debemos olvidar, en efecto, que tras la Primera Guerra Mundial, la Revolución Rusa había aparecido para muchos intelectuales - y no solo para los intelectuales- como el nacimiento de un mundo y de seres nuevos, como la próxima etapa en el progreso de la Humanidad. Este progreso debía consistir en la abolición de la economía de mercado capitalista, la desaparición de las formas de explotación del trabajo humano y del despilfarro de los recursos naturales sobre los cuales este sistema reposaba. Pero se trataba también de reemplazar las formas «burguesas» de la democracia al servicio de las clases poseedoras por una forma supe- 
rior de democracia al servicio del pueblo. En fin, una vez más Occidente, pero otro Occidente, se presentaba como la medida y el espejo de los progresos de la Humanidad.

Esta es la ocasión de recordar claramente que no existe un solo Occidente, sino varios, y que fue primero en este mismo Occidente donde se desarrolló la crítica del sistema económico y político que formaba su fortaleza. Comprendemos pues que al salir de la Segunda Guerra Mundial, en el curso de la cual la Rusia de Stalin había combatido al lado de los Aliados y contribuido en gran parte a la victoria, y antes de que, poco a poco, los regímenes socialistas revelen ser lo que eran, regímenes de dictadura y de explotación de las masas, las corrientes intelectuales que dominaron entonces en las ciencias sociales y la filosofía, al menos en Francia, fueron el marxismo (Althusser), el estructuralismo (Lévi-Strauss) y el existencialismo de Sartre, quien, por su parte, ponía delante la libertad imprescriptible del individuo. Esto le oponía en el plano teórico a los marxistas y a Lévi-Strauss, quienes ponían por delante la existencia de estructuras impersonales, conscientes o inconscientes, y sus consecuencias estructurales. Pero en el plano político, Sartre se había colocado rápidamente al lado de los partidarios de la revolución para derribar el orden burgués.

La desaparición progresiva de los imperios coloniales y de los regímenes socialistas solo podía socavar este mundo intelectual europeo y provocar una crisis que nos ha hecho, según la expresión de Lyotard prestada por arquitectos de la época, entrar en «la condición posmoderna». Para Lyotard, esta condición nueva significaba dos cosas para el trabajo del pensamiento: por una parte, la muerte de todos los «metarrelatos», es decir, explicaciones sobre la historia y la diversidad compleja de las sociedades a partir de una primera causa, eficaz en última instancia, como la noción de «modo de producción» para los marxistas o la de «estructuras inconscientes del espíritu» para Lévi-Strauss. Por otra parte, la condición posmoderna significaba entonces necesariamente el regreso del sujeto como actor de su propia historia. Es lo que ilustró en Francia la segunda parte de los trabajos de Foucault, quien, tras haber seguido a Althusser y Lévi-Strauss y proclamado «la muerte del sujeto", se dedicó luego a analizar los procesos de subjetivación de los individuos en el marco de los diversos regímenes de poder. Es entonces cuando parece imponerse como tarea teórica la urgencia de «deconstruir», según una expresión prestada por Derrida, todos los discursos elaborados hasta entonces en filosofía y en todas las disciplinas de humanidades y ciencias sociales.

Deconstruir una disciplina no tiene nada sorprendente en sí. Es un momento necesario y normal en el desarrollo de todas las ciencias, tanto 
las de la naturaleza como las de la sociedad. Es un paso que se impone tras la aparición de nuevas formas de interpretar los hechos ya conocidos, o frente al descubrimiento de nuevos hechos. Pero existen dos maneras de deconstruir una disciplina. Una lleva a la disolución y eventualmente a la desaparición de esta disciplina; la otra se apoya en las críticas positivas producidas durante su deconstrucción, abriendo una vía a la reconstrucción de esta misma disciplina sobre una base más rigurosa, más crítica y por ello analíticamente más eficaz de lo que era antes.

Se hace pues indispensable indicar algunas de estas críticas positivas de la antropología, ya que permiten de antemano derreconstruirla. Además, su propia existencia demuestra que no es posible hacer una amalgama de todas las publicaciones que se reconozcan del posmodernismo y de sus autores. Marcus no es Rabinow, James Clifford no es Crapanzano, y Stephen Tyler no es Michael Fischer. Y ninguno de ellos era Clifford Geertz, que les inspiró a todos. Cada uno es solo quien es. Pero antes de enumerar algunas de las mayores críticas, me parece importante resaltar que el tema «El fin de la antropología» se inscribe más bien en la primera manera de deconstruir una disciplina, la que lleva a su desaparición.

¿Cómo puede una disciplina desaparecer? Hay dos vías para esto. Una disciplina puede desaparecer o bien porque su propio objeto deja de existir, o bien porque aunque su objeto sigue existiendo, esta disciplina que pretendía dárnoslo a conocer se mostró incapaz de realizar su objetivo. Tomemos la primera hipótesis. ¿El objeto de la antropología desapareció? Los nuer, los kachin, los tikopia, los baruya, no han desaparecido. Existen. Pero sus sociedades, sus modos de vida y de pensamiento se han transformado con la colonización y siguen haciéndolo desde entonces. ¿Pero acaso una ciencia desaparece porque sus objetos evolucionan? En este caso, la Historia como disciplina habría dejado de existir hace tiempo ya que todas las sociedades del pasado que estudia o bien desaparecieron o bien han seguido existiendo bajo formas completamente diferentes. Quizá entonces la antropología debería desaparecer porque, para dar ejemplos, hoy gran parte de la población de Trobriand vive en Nueva Zelanda o en Los Angeles. Pero esto presupone implícitamente que la antropología no tenía otro objeto de estudio más que las denominadas sociedades "primitivas», «tradicionales», «preindustriales», «no-urbanas» o «no-occidentales». Este presupuesto es en efecto un a priori ideológico al cual la antropología ya tuvo que enfrentarse desde la publicación de Ancient Society de Morgan quien, en este libro, distribuye todas las sociedades conocidas por él en tres grupos a lo largo de una escala de los progresos de la humanidad, desde el «salvajismo» a la «barbarie» y luego 
a la «civilización», representada por supuesto a sus ojos por las sociedades de Europa y de América del Norte, liberadas por fin de los regímenes feudales de la Edad Media, y conducidas por las fuerzas de la civilización industrial y mercantil moderna y por la democracia. El desarrollo de la antropología urbana, de los estudios de género, de la antropología médica, etc., muestran bien que no es así.

Pasemos entonces a la segunda razón que podría provocar la desaparición de nuestra disciplina. Como hemos visto, la cuestión que se plantean la antropología, la historia y otras ciencias sociales es la misma: ¿cómo comprender y explicar la existencia de lo que nunca ha formado parte de su manera de vivir y de pensar? El argumento ya no es el de la desaparición del objeto de la antropología, sino el de su incapacidad de existir como ciencia. Desde su origen, la antropología solo habría producido relatos etnográficos que no serían más que proyecciones de ideologías por observadores occidentales sobre las sociedades que estudiaban. Por esta crítica han surgido dos posicionamientos. Uno es el de George Marcus, quien dejaba por lo menos la esperanza de una «New Ethnography» (Nueva etnografía); la otra, radicalmente crítica, es la de Stephen Tyler, cuestionando que una nueva etnografía fuera posible. Para Marcus y Clifford, las etnografías escritas por Malinowski, Leach, Evans-Pritchard, etc., habrían sido ante todo unas «narracionesficciones» (Clifford, 1985: 97-98) escritas con la complicidad de dos partes comprometidas en el conocimiento de la otra, el etnólogo y sus informantes, y producen unas "fictions that each side accepts» (ficciones aceptadas por ambos lados) (Marcus, 1998: 110). Según Marcus, podemos hacerlo de otro modo y mejor. En cambio, para Stephen Tyler, todo relato etnográfico está condenado a ser un «reality fantasy of a fantasy reality» (una realidad fantástica de una fantástica realidad) (Tyler, 1986: 139). Para él, desde su nacimiento la antropología ya había muerto como ciencia, porque todo relato etnográfico por sí mismo "no es en sí ni un objeto que representar, ni la representación de un objeto [...] porque ningún objeto de ningún tipo precede o plantea ninguna limitación a la etnografía» (Tyler, 1986: 131). Reconocemos allí la posición teórica de Derrida y de Paul de Man, para quien era imperativo "deconstruir la ilusión de la referencia, la posibilidad de que un texto reenvíe a una realidad no-textual» (de Man: 1986: 19-20). Sin embargo, es difícil creer que los acontecimientos y las prácticas de las otras sociedades transmitidas por los antropólogos hayan sido todos alucinaciones (a fantasy reality) y que, por ejemplo, los atentados del 11 de septiembre de 2001, reivindicados por Ben Laden y Al Qaeda no hayan sido más que un show televisado (a reality fantasy). 
Observo que la mayoría de estas críticas se refirieron principalmente a un solo aspecto del oficio del antropólogo: el momento en el cual escribe para dar cuenta de sus datos de campo y de los análisis que hizo a partir de ellos. La crítica realizada por Clifford sobre las monografías escritas por los etnólogos es refutable. Una monografía etnográfica, de hecho, no es una obra literaria (aunque pueda tener cualidades literarias), y no lo es por dos razones. A diferencia de Macbeth, personaje surgido de la cabeza de Shakespeare, el Kula existía mucho antes de que Malinowski lleguase a Kiriwina y ha seguido existiendo después de su salida. La segunda razón consiste en que nadie puede completar o refutar la obra de Shakespeare, mientras que los trabajos de Fred Damon, Nancy Munn, Anette Weiner y otros, 50 años después de Malinowski, han podido completar, enriquecer y corregir su análisis del Kula. En cambio, curiosamente, hay dos momentos esenciales del oficio de antropólogo que no han sido objeto de una crítica en profundidad. El denominado momento de la «observación participante» realizada en el campo, y el momento en el cual se elabora la interpretación de los datos recopilados, un momento que empieza en el campo pero que se prosigue más allá. Quizá estos olvidos sean debidos al hecho de que James Clifford, el mismo que criticó tanto las formas de los otros en «Writing Culture», nunca había realizado trabajo de campo. Pero dejemos las provocaciones de Tyler o las exageraciones de Marcus para regresar sobre algunos resultados positivos almacenados por los críticos de los colegas llamados "posmodernos».

Uno de ellos - muy importante- es haber puesto en evidencia la ausencia o la casi-ausencia, en las publicaciones de numerosos antropólogos, del análisis de las relaciones coloniales que sufrían las poblaciones en el mismo momento en que hacían su trabajo de campo. EvansPritchard, por ejemplo, apenas mencionó en su obra la presencia de las tropas británicas enviadas a reprimir las tribus alrededor del lugar de su investigación. Esto no quiere necesariamente decir que Evans-Pritchard fuera cómplice o agente del colonialismo, ni tampoco que lo que escribió sobre el parentesco y las estructuras políticas de los nuer fuera falso. Por otra parte, no todos los etnólogos guardaron el silencio sobre el contexto colonial en su trabajo. Citemos a Firth, por ejemplo, que ha sido claro sobre lo ocurrido en Tikopia, o France Germaine Tillion, que investigó en Argelia en plena guerra colonial y realizó denuncias públicamente. Adicionalmente, los antropólogos estuvieron en lo cierto al poner en evidencia los presupuestos contenidos en las nociones de "progreso" y de "civilización». Con más razón aún, ya que la ideología colonial no ha muerto. Se ha transformado en una ideología de los Derechos del Hombre que otorga a los Occidentales y a sus aliados nuevas razones 
para juzgar otras sociedades e interferir en su desarrollo. Sobre todos estos puntos, los Subaltern y Post-Colonial Studies han tomado el relevo de las primeras críticas y su aportación hoy es considerable (Ludden, 2001; Pouchepadass, 2004: 67-79).

Otro punto importante fue la petición lanzada por George Marcus y otros para que las publicaciones de los antropólogos hicieran entender una pluralidad de voces y no solo la del antropólogo. El riesgo era por supuesto afirmar posteriormente que todas estas voces son válidas y que la del antropólogo no aporta nada específico que le otorgue un peso particular en este concierto. Hubo otras críticas que tuvieron sus orígenes no ya en las transformaciones de las relaciones de fuerza y de interés entre Occidente y el resto del mundo, sino en las luchas nacidas en el mismo interior de los países occidentales y que también han contribuido a revelar bajo un nuevo prisma los trabajos de nuestros predecesores. Me refiero a las críticas, desarrolladas primero en los Estados Unidos y en los países anglosajones, de todas las discriminaciones, segregaciones y exclusiones que existen en nuestras sociedades, pero también en las demás, por unas razones de diferencia de sexo, de color de la piel, de la fe religiosa, etc. Son unas discriminaciones que no están forzosamente percibidas como tales en otras sociedades, por ejemplo en el Islam, donde se considera como fundado en el orden religioso aspectos como la subordinación de las mujeres a los hombres. En Occidente, ya están denunciadas en nombre de la idea de la igualdad de derechos entre todos los seres humanos, idea que seguramente no estaba incluida en el principio de la vida social en el sistema de castas de la India, en el mundo islámico, en el de los baruya, y tampoco lo está hoy en Europa en múltiples aspectos de la vida social. Sobre este punto, James Clifford (1986) hizo obra útil demostrando que en el libro, por cierto notable, de Godefrey Lienhardt, Divinity and Experience. The Religion of the Dinka (Lienhardt, 1971), las mujeres no aparecían salvo una vez cuando una de ellas explicó al antropólogo lo que era el ganado para los hombres. Es probablemente un caso de androcentrismo, pero también hay que considerar que es notoriamente difícil para un hombre entrar en contacto con mujeres en ciertas sociedades.

Mencionaré un último punto en la revisión de las contribuciones hechas por la crítica de los posmodernistas. Estos han contribuido enormemente al rechazo de toda interpretación esencialista sobre la alteridad de los demás. La crítica no es nueva, y ya Boas en la primera década del siglo XX demostró que las sociedades de la Costa Noroeste estaban abiertas las unas a las otras y efectuaban intercambios entre ellas. Esto no quiere decir que no haya en todas las sociedades aspectos dominantes de su cultura y de su organización como componentes principales de su 
identidad y que sean vividos como tales. Comprenderemos fácilmente que estos caracteres dominantes no pueden desaparecer de un día para otro ya que son los protagonistas de la reproducción de estas sociedades.

En resumen, ninguna de estas críticas indica que estemos viviendo, según la expresión de Sahlins, "el crepúsculo de la antropología». La conclusión se impone. Hemos de seguir «deconstruyéndola» siempre más y siempre mejor, pero de forma tal que la podamos reconstruir sobre una base más eficaz frente a los desafíos del mundo globalizado en el cual viviremos y ejerceremos nuestro oficio en el siglo XXI.

A continuación, quisiera volver a la pregunta "¿cómo comprender la alteridad de los otros?» e indicar cómo y por qué para mí la antropología tiene ahora más capacidad para responder satisfactoriamente a esta cuestión, aunque bajo ciertas condiciones. Por una parte, la alteridad social e histórica de los demás debe ser relativa y no absoluta. Necesitamos que los otros sean capaces de entender aquello que se ha inventado para interpretar el mundo que rodea a los hombres y cómo los hombres lo rodean, ya se trate del «Dreaming Time» aborigen, del budismo mahayana o del marxismo. Y es esencial subrayar que si los hombres pueden comprender la alteridad social de otros humanos, no tienen la obligación de adherirse a los principios y valores que produjeron esta alteridad, ni la obligación de ponerlos en práctica para sí mismos. Cada uno puede averiguar a través de su propia experiencia de los otros que estas dos condiciones existen de forma concreta y restan todo fundamento a las tesis de los que defienden la idea de una incomunicabilidad fundamental entre las culturas.

Ser antropólogo es ejercer un oficio de producción de conocimientos verificables, y por tanto refutables, cuyo objetivo y cuyos usos no son los perseguidos por los misioneros, los militares o los negociantes que intervienen en el seno de sociedades que no son las suyas. Y para ejercer su oficio, no basta que la alteridad de los otros sea "cognoscible", sino que también el antropólogo haya puesto los medios para conocerla.

Para eso, el antropólogo debe empezar por construir en sí mismo, un Yo cognitivo que sea diferente de su Yo social y de su Yo íntimo. Por Yo social me refiero a aquel que hemos podido heredar al nacer si somos hijo o hija de alguien — por ejemplo, uno puede ser hijo de un Brahmán—, o que hayamos construido a lo largo de la existencia. Nuestro Yo íntimo es aquel que se modeló desde el nacimiento por nuestros encuentros felices o dolorosos con los otros. Es el Yo de los deseos, de las felicidades, de los sufrimientos, el Yo que modela una sensibilidad, es decir, también una forma de ser con los demás. Por supuesto, nuestro Yo social y nuestro Yo íntimo se mezclan indisolublemente y en el antropólogo no se dife- 
rencian de los de cualquier otro. Lo que le distingue consiste en que debe construir en él otro Yo, un Yo cognitivo. Este Yo cognitivo es primero un Yo intelectual que se fabrica antes de ir al trabajo de campo a partir de elementos «ideales» ${ }^{1}$ : conceptos, teorías, controversias, aprendidos en la universidad o por otras partes y que lleva la marca de su tiempo. En tal época, somos con gusto estructuralistas, y en otra, posestructuralistas. Pero sea cual sea su época, el Yo cognitivo es un Yo que debe aprender a descentrarse frente a los demás Yo, el Yo social y el Yo íntimo. Es a la vez un Yo ético y político que deberá continuamente mantenerse en estado de vigilancia crítica en contra de la intrusión siempre posible de los juicios que su propia sociedad había ya elaborado sobre las demás sociedades. Descentrarse significa entonces suspender su juicio y devolver al horizonte de la conciencia los presupuestos de su cultura y de su sociedad, incluso los de su propia historia de vida.

Pero este Yo cognitivo no es solo un Yo hecho de ideas. Debe implicarse en una práctica, la de la llamada observación "participante», en la cual el antropólogo se sumerge en otra sociedad distinta a la suya o en un entorno diferente al suyo para estudiarlos y comprenderlos. Pero entonces se plantea un problema temible que se queda ampliamente sin formular en las críticas de la antropología: porque, ¿qué significa "observar»?, y ¿observar "participando» en qué?, y ¿hasta dónde? Participar en la vida de los otros es en efecto otra cosa distinta a irse de vez en cuando a cazar en compañía de un grupo de inuit y contribuir esos días alimentándose a sí mismo y a los otros. Haría falta, para pretender "participar» en la vida de los otros, que el etnólogo haga "como otros», que tome esposa en la sociedad, que tenga niños y los eduque, que participe en sus ritos, etc. Es lo que no hacen la gran mayoría de los antropólogos, y además no es necesario que lo hagan para entender las formas de pensar y de actuar de aquellos con los que han ido a vivir. Existe en efecto una diferencia fundamental entre el etnólogo y aquellos con los que ha ido a vivir, desde el punto de vista del uso de los conocimientos que adquiere poco a poco de sus principios de pensamiento y de acción. Porque para aquellos que le rodean, los conocimientos que tienen de sus mitos, de sus ritos, de sus reglas de parentesco, de las costumbres de los animales cazados, etc., sirven para producir sus condiciones concretas de existencia y también para reproducir hasta un cierto punto su sociedad. Pero para el etnólogo,

1. Nota de la traductora: aquí «los elementos ideales» se refieren a la esfera de las ideas y no de la perfección. Este concepto tiene su origen en el trabajo de Maurice Godelier publicado en 1984, L'idéel et le matériel. Pensées, économies, sociétés (Paris, Fayard), y traducido al español como Lo ideal y lo material. Pensamientos, economías, sociedades en 1989 (Madrid, Taurus). 
estos conocimientos adquiridos con dificultad, siempre incompletos, no le sirven casi nunca para producir las condiciones necesarias de su propia existencia en el seno de la sociedad adonde fue. Le sirve ciertamente para comprender a los otros, pero no para actuar como ellos y con ellos en todas las circunstancias de su existencia. Porque acumulando estos conocimientos, el antropólogo se produce al mismo tiempo como tal, como antropólogo, y esto es un estatus que le confiere un lugar en su propia sociedad. Esto aclara la naturaleza del lugar que ocupa un etnólogo cuando está haciendo su trabajo de campo. Es un lugar que debe construir, y además de manera muy difícil: un lugar que le sitúa a la vez fuera de su propia sociedad pero también dentro, y al mismo tiempo dentro de la sociedad donde ha ido a vivir pero también fuera. Es entonces un lugar muy peculiar, a la vez concreto y abstracto, que hace de la presencia y del trabajo del antropólogo una experiencia original de las relaciones que un hombre o una mujer puede tener con los otros y consigo mismo.

Sean lo que sean los límites de su participación a la vida de los otros, es en este marco que les observa. Pero, ¿qué observa? En principio, todo tipo de interacciones produciéndose alrededor de él en situaciones concretas muy diversas entre los individuos y los grupos que componen la sociedad donde ha venido a vivir y trabajar. Por supuesto, su campo de observación no se extiende a toda la sociedad pero está estructurado por varios tipos de acontecimientos que se lo aclaran ampliamente. Todos los días, en efecto, los acontecimientos se repiten alrededor de él. La gente se levanta, come, se va de caza o al campo, vuelven, se acuestan, etc. Los acontecimientos son recurrentes, previsibles, ofrecidos cada día para su observación. Ocurren otros acontecimientos, pero no son recurrentes, aunque hasta cierto punto sí son previsibles. Un accidente de caza, un asesinato y sus consecuencias, por ejemplo. También existen acontecimientos cíclicos que vuelven tras varios años y que conciernen a todos los miembros de la sociedad, como las iniciaciones masculinas y femeninas de los baruya, por ejemplo. Sin embargo, al lado de estos acontecimientos que se ofrecen de una u otra manera al observador, el antropólogo debe además poner en marcha observaciones provocadas por él mismo, emprendiendo grandes investigaciones sistemáticas que a veces duran meses y estudian diversos aspectos de la vida social de los otros, sus prácticas agrícolas, sus ritos de iniciación, las formas de propiedad, así como el uso del suelo y del territorio. Estas investigaciones, correlacionándose, producen resultados, descubrimientos muchas veces inesperados por el etnólogo, y contribuyen a hacerle comprender todavía mejor la lógica de los modos de pensamiento y de acción de la gente que le rodea. 
Una vez estas observaciones son recopiladas, lo cual pueden exigir años, hay que interpretarlas y luego darlas a conocer. El etnólogo debe entonces pasar a otras formas y a otros niveles de trabajo. Tendrá por ejemplo que comparar sus datos con los recopilados en otras sociedades por otros antropólogos. Así fue como entendí que la terminología de parentesco de los baruya era de tipo iroqués, y como sabía que este mismo tipo de terminología de los iroqueses era asociado a un principio de descendencia matrilineal, pero vi que con los baruya era asociado con un principio de descendencia patrilineal, llegué a plantearme problemas teóricos en relación con las condiciones de aparición de los sistemas de parentesco de tipo iroqués y de su distribución en diversos continentes (Godelier, 2004). Estas cuestiones teóricas se me presentaban a mí pero no les interesaban de ninguna manera a los baruya. ¿En qué, para los baruya, el hecho de saber que su terminología de parentesco era del mismo tipo que el de ciertos indios de América podría tener algún interés en su existencia cotidiana? Esto podría quizás haber interesado a algunos baruya que habían ya empezado a frecuentar las universidades, o a interesarse en las costumbres de los blancos o de otras sociedades. Pero fuera de este impacto muy limitado, este proceso intelectual del antropólogo, totalmente legítimo desde el punto de vista del trabajo de conocimiento de los modos de existencia de la humanidad, no contribuía a ninguno de sus problemas existenciales.

Este análisis sobre el estatus diferente de los conocimientos compartidos por los actores mismos y por el antropólogo deja claro que para los actores estos conocimientos concretos constituyen verdades existenciales, mientras que para el etnólogo son los conocimientos abstractos que serán el material con el cual intentará construir verdades científicas. Porque el hecho de descubrir que los baruya tienen un sistema de parentesco patrilineal con terminología de tipo iroqués permite comprender en qué y para qué las nociones de paternidad, maternidad, hermandad, son diferentes para ellos y para un occidental. Si en efecto todos los hermanos de mi padre son igualmente padres para mí, si todas las hermanas de mi madre son madres para mí, si todos los niños son hermanos y hermanas, cuando el esposo de mi madre muere, yo todavía tengo otros padres. Y si no tengo a una hermana para entregar a cambio de una esposa, tengo el derecho y la posibilidad de cambiar las hijas de los hermanos de mi padre porque ellas también son mis hermanas. Frente a estos problemas múltiples, un baruya dispone, gracias a la naturaleza de su sistema de parentesco, de solidaridades y de asistencias mutuas que no existen en nuestra sociedad. Y esto, el etnólogo puede observarlo y averiguarlo. 
Estas verdades existenciales, por muy diferentes que sean de sociedad en sociedad, son respuestas a interrogaciones existenciales presentes en todas las sociedades, bajo formas particulares, por supuesto. Por doquier y en todas las épocas, los hombres se preocuparon por comprender lo que significa nacer, vivir y morir; por doquier se cuestionaron sobre las formas del poder que podían ejercer legítimamente sobre ellos mismos y sobre los otros. Por doquier se preocuparon por definir las relaciones que los hombres deben tener con sus antepasados, con los espíritus de la naturaleza, con los dioses o con Dios. Por doquier se preocuparon por dar un sentido al universo que les rodea, montañas, bosques, mar, etc. Y por doquier dieron un sentido a las desigualdades que instituyen entre los géneros, entre las castas, etc., o bien para legitimarlas o bien para contestarlas. En fin, uno de los objetos de la antropología, como de la historia también, consiste en comparar estas respuestas culturales y sociales y explicar si son posibles las condiciones de aparición y de desaparición en el espacio y el tiempo. Estos son niveles de trabajos teóricos que desbordan y sobrepasan la experiencia singular que se hace uno de una sociedad en un lugar dado.

Para terminar, quisiera ilustrar con mi propia experiencia lo que me aportaron mis esfuerzos de deconstrucción y de reconstrucción de la antropología. Emprendiendo la deconstrucción de algunas evidencias antropológicas, conseguí considerar como muertas para mí algunas verdades antropológicas asumidas como insoslayables. Pude demostrar que ni las relaciones de parentesco, y mucho menos la familia, son en ninguna parte el fundamento de las sociedades. Y esta conclusión vale para todas las sociedades, incluso las sociedades sin clase y sin casta que parecían poseer la evidencia de lo contrario y que bautizábamos en los manuales las «kin-based societies» (sociedades basadas en el parentesco).

Cuando emprendí mis investigaciones sobre los sistemas de parentesco y sus metamorfosis pasadas o recientes, me preocupé también por un aspecto dejado casi siempre en el olvido: la manera bajo la cual las sociedades, según su sistema de parentesco y sus principios de descendencia, unilineales, bilineales, indiferenciados, se representan el proceso de la fabricación de los niños, de su concepción. Comparé entonces las representaciones de 22 sociedades de Oceanía, de África, de Asia y de América, así como el parentesco cristiano europeo. Para mi gran sorpresa, descubrí que todas las sociedades, a pesar de las diferencias entre sus sistemas de parentesco, tenían un punto en común. Todas, bajo una forma u otra, afirmaban que un hombre y una mujer uniéndose sexualmente no eran suficientes para fabricar un niño. Lo que fabricaban con su esperma ( $b a$ ruya) o con su sangre menstrual (trobriand) era el feto, pero para que este 
feto llegara a ser un niño hacía falta la intervención de otros agentes invisibles y más poderosos, de antepasados que venían a reencarnarse en el cuerpo del niño (inuit, trobriand) o el Dios de los cristianos que introduce en un momento elegido por él un alma en el cuerpo del niño.

En otras circunstancias, he debido reexaminar el famoso análisis del Don desarrollado por Mauss, retomado y criticado por Lévi-Strauss. Esto me hizo descubrir que al lado de las cosas que se venden y de las que se regalan, existen cosas que Mauss y Lévi-Strauss habían dejado sin analizar, cosas que no hemos de vender y tampoco dar, sino que las debemos guardar para transmitirlas. Estas «cosas» son siempre portadoras de un aspecto superior de la identidad de los grupos humanos. Corresponden a lo que llamamos el campo de lo "sagrado». Pero hemos de tener cuidado: lo sagrado sobrepasa lo religioso e incluye lo político. En nuestras sociedades democráticas, la Constitución, que fija las reglas de la convivencia para millones de personas, es un objeto que no se puede vender ni comprar. Lo que se puede comprar son los votos de los electores, pero no la Constitución en sí, que no es una mercancía. La existencia de esta área de nuestra vida que no entra en el campo de los intercambios mercantiles ni de los intercambios de dones ni contra-dones, equivalentes o no, muestra los límites de la tesis de Lévi-Strauss y otros, para quienes la vida social entera se basa en el intercambio: intercambio de mujeres, intercambio de bienes y de servicios, intercambios de signos y sentidos como el parentesco, la economía y la cultura. De hecho, olvidaron que para que las cosas se intercambien y circulen, también debían existir otras que no pudieran circular ni intercambiarse.

Con todos estos análisis llegué a plantearme dos problemas que resultaron estar conectados: uno era la presencia y el papel de los nudos centrales imaginarios en el seno de las relaciones sociales. Un ejemplo en el caso del parentesco: la afirmación en las sociedades patrilineales de que el esperma del hombre fabrica el cuerpo del feto y que la mujer no es más que un receptáculo para este esperma. O la afirmación contraria en las islas Trobriand de que el esperma no fabrica el cuerpo del feto sino que es la sangre menstrual de la madre la que lo fabrica. También lo es la siguiente afirmación de los baruya: el sol es quien dio al antepasado del clan de los kwarrandiar, el «Kwaimatnié», los objetos sagrados y las fórmulas secretas que permiten iniciar a los niños y transformarlos en guerreros después de haberlos transportado por los aires en un camino de fuego hasta Brevegareubaramandeuc, donde encontró a hombres y los organizó en una sociedad capaz de reproducirse como tal.

Por supuesto, estos relatos se refieren a hechos — según nuestro criterio imaginarios- escenificados a través de ritos de iniciación y que 
constituyen prácticas simbólicas que transmutan los hechos imaginarios en relaciones sociales reales donde los individuos ocupan diferentes lugares, que están vinculados entre sí según su género, su edad y sus aptitudes para transformarse en grandes guerreros o chamanes. En oposición a Lévi-Strauss, pero en la línea de Geertz, no asistimos aquí a la "primacía» de lo simbólico sino más bien a la «primacía» de lo imaginario a través de lo simbólico.

El caso de los baruya planteaba un problema adicional, sugiriendo a su vez una respuesta a este problema. Porque, según la tradición baruya, esta sociedad apareció recientemente, alrededor del siglo XVIII, según mis cálculos. En su origen, la formaban un grupo de hombres y mujeres que pertenecían a muchos clanes de una tribu, los yoyué, que huyendo de una matanza encontraron refugio y socorro con los andjé, localizados a algunos días de camino. Tras varias generaciones, los descendientes de los refugiados asesinaron a sus anfitriones y se apoderaron de una parte de su territorio. Entonces, empezaron a edificar su propio centro de iniciación y a iniciar ellos mismos a sus jóvenes para convertirlos en futuros guerreros y chamanes. Vemos que en este caso no son las relaciones de parentesco ni las relaciones económicas entre los individuos y los grupos los que hicieron de ellos una sociedad. Son lo que en Occidente se llama las relaciones político-religiosas; "religiosas» porque en el curso de las iniciaciones los dioses y los antepasados cooperan con los maestros de las iniciaciones para iniciar a los jóvenes, $\mathrm{y}$ "políticas» porque las iniciaciones deben purificar a los chicos de lo que recibieron de las mujeres y prepararlos para gobernar su sociedad sin ellas. En fin, son estas relaciones político-religiosas las que instituyen y legitiman la soberanía que los baruya ejercen en su territorio y cuyos límites son conocidos, cuando no reconocidos, por las tribus vecinas.

Pasemos al ejemplo de los tikopia que, según las tradiciones recopiladas por Firth, fueron invadidos por grupos provenientes de otras islas: Ontong, Java, Pukapuka, Rotuma, Anuta, etc., que combatieron sin cesar hasta que el antepasado del clan de los kafika instituyó ritos en los cuales cada grupo tenía su función y su sitio, hasta formar una sociedad. Cuando fue asesinado por un rival, los dioses polinesios transformaron a este fundador en Atua, dios de la isla de Tikopia, y sus descendientes directos ocuparon desde entonces el primer lugar en los ritos porque su cuerpo poseía el maná de un dios. Por tanto, en Tikopia también fueron las relaciones político-religiosas las que formaron, con diversos grupos humanos sin relación de parentesco, una sociedad (Firth, 1967: 15-30).

Daré un último ejemplo que nos trae a nuestro siglo y al mundo global en el cual vamos a partir de ahora a ejercer nuestro oficio. Arabia 
Saudita es un Estado que no existía al principio del siglo XVIII. Nació del encuentro y de las ambiciones de dos hombres entre 1740 y 1742 : Mohammed Abd-al-Wahhab y Mohammed Ibn-Saoud. El primero, un reformador religioso, miembro de una confederación tribal que le había expulsado porque llamaba a la Yihad contra los malos musulmanes que, según él, poblaban los lugares santos del Islam: La Meca y Medina. En la corriente del Hanbalismo, una de las cuatro corrientes del sunismo aparecida en el siglo IX, Mohammed Abd-al-Wahhab se oponía a toda innovación, a toda interpretación personal del Corán, y quería imponer a todos los musulmanes la vuelta a las tradiciones de los primeros creyentes. El segundo, Mohammed Ibn-Saoud, un jefe de tribu ambicioso que reinaba sobre Dar'iya, una aldea del Najd en Arabia Central, deseaba someter a todas las tribus que le rodeaban. Pero en el mundo musulmán hacía falta para eso una legitimidad religiosa. Es lo que le proporcionaba Mohammed Abd-al-Wahhab predicando la Yihad, y que necesitaba el apoyo de una fuerza política y militar. El encuentro entre ambos hombres fue la alianza de dos tipos de fuerzas sociales, religiosas y políticas, y eso fue el acta de nacimiento del primer Estado saudí que llegó en 1802-1804 a conquistar a los lugares santos del mundo musulmán, La Meca y Medina. El Wahabismo se hizo entonces religión de Estado (Al-Rasheed, 2002).

Saltemos un siglo y medio. En 1938 se descubrió petróleo en Arabia Saudí, y el país se situaría en cuarto lugar a la cabeza de las reservas mundiales de petróleo. En 1945, Roosevelt firma con el Rey Saoud de la época un tratado por el cual los Estados Unidos se comprometen a proteger el reino en contra de sus vecinos, Irak e Irán, a cambio de su petróleo. En 1979, el ayatolá Jomeini hace del Irán chiíta la primera República Islámica, mientras que los rusos invaden Afganistán. Millares de voluntarios musulmanes, entre ellos Ben Laden, armados por los estadounidenses y financiados por Arabia Saudita, combaten durante una década contra los rusos, que se verán obligados a retirarse de Afganistán en 1989. Después de su salida, llegó el reino de los talibanes y la creación de Al-Qaeda, i.e., «la Base», creada para lanzar la Yihad ya no solamente en contra de los malos musulmanes como en el siglo XVIII, sino contra los judíos, los cristianos y en general contra el Occidente materialista, por haber humillado y explotado a los árabes y a los musulmanes desde el siglo XIX.

Una vez más, ya no son las relaciones de parentesco ni las relaciones económicas las que explican la formación de esta nueva sociedad. La economía de las tribus de Arabia Central en el siglo XVIII no impulsaba por sí misma la formación de un Estado, no más que las relaciones de 
parentesco en el seno de las tribus o de las confederaciones tribales; aunque una vez el Estado estuvo en vías de formación, los matrimonios y las alianzas entre grandes «casas» y tribus reforzaron el poder de la dinastía de los Saoud (Godelier, 2007: 221-248).

Es aquí donde estamos. Después de los acontecimientos del 11 de septiembre que conmovieron de nuevo las relaciones de fuerza a nivel mundial, hemos asistido a la quiebra de la intervención americana en Irak y a la pérdida de la hegemonía política mundial de los Estados Unidos. Otros pueblos, otras naciones, China, India, Rusia, están a su vez influyendo en las relaciones entre Occidente y el resto del mundo sin que esto signifique la desaparición del capitalismo sino un nuevo principio para la afirmación o la reinvención de las identidades culturales y políticas de muchas sociedades locales. A la integración cada vez más fina de las economías en el sistema mercantil capitalista corresponde el contrapeso del movimiento de segmentación de los regímenes políticos y de resistencias de las identidades locales.

Observamos que nada en estos procesos deja prever la muerte próxima de la antropología. Al contrario, esta es una de las disciplinas de las ciencias sociales que mejor puede, con la historia, hacernos entender la complejidad del mundo global donde nos encontramos y la naturaleza de los conflictos y de las crisis que le atraviesan y que no están dispuestos a desaparecer. En este mundo, sería irresponsable e indecente por parte de los antropólogos dejar de hacer su trabajo sobre el conocimiento de los otros, así como sobre ellos mismos y, como no, compartir sus resultados.

\section{Referencias bibliográficas}

Al-Rasheed, M. (2002). A History of Saudi Arabia. Cambridge: Cambridge University Press. Clifford, J. (1985). De l'ethnographie comme fiction. Conrad et Malinowski. Études Rurales: 97-98.

Clifford, J. (1986). Partial Truths. En J. Clifford and G. Marcus, Eds.

De Man, P. (1986). The Resistance to Theory. Minneapolis: University of Minnesota Press. Firth, R. (1967). Tikopia Ritual and Belief. Boston: Beacon Press.

Godelier, M. (2004). Métamorphoses de la Parenté. Paris: Fayard.

Godelier, M. (2007). Au Fondement des Sociétés Humaines: Ce que nous apprend l'Anthropologie. Paris: Albin Michel.

Lienhardt, G. (1961). Oxford: Oxford University Press.

Ludden, D. (Ed.) (2001). Reading Subaltern Studies: Critical History, Contested Meaning and the Globalization of South Asia. New Delhi: Parmanent Black.

Pouchepadass, J. (2004). Que reste-t-il des Subaltern Studies? Critique Internationale, 24: 67-79. 
Marcus, G. (1988). Ethnography through Thick and Thin. Princeton: Princeton University Press.

Tyler, S. (1986). From Document of the Occult to Occult Document. En Writing Culture. The Poetics and Politics of Ethnography. J. Clifford y G. Marcus. Berkeley: University of California Press.

Vassiliev, A. (2002). The History of Saudi Arabia. London: Saqi Books. 
